\title{
That was then, this is now: Māori Performance Research Comes of Age
}

Then. The way I see it, Māori Performance Research as it is coming to be practiced now started in the late 1990s at the University of Canterbury. Te Rita Papesch and I had been thrown together there as its only two female heads of school she in Māori Studies, I in Theatre and Film Studies. Bonded by gendered necessity in a male-dominated academic environment, our chat ran along the lines of 'You show me your research, and I'll show you mine'. She started talking about Kapa Haka, I started talking about Performance Studies, and twenty years on (although we've moved on from Canterbury), we're still talking. After all, not only is the personal political, it is also simultaneously academic and performative. This then is a personal account, my own version of the story of how we have come to be here now in this room discussing a field of study that I will, today, call Māori Performance Research: research focused on Māori performance, performance research from a Māori perspective, performance research by and for Māori academics and artists. These are not the same thing, but an evolving mix of old and new ways both of knowing about performance and of performing that knowledge.

From the start, Te Rita and I have been careful to delineate our differences as well as our alignments. In fact, our first foray into public was with a joint symposium presentation we titled 'Crossing the Cultural Divide?' in 2001. It was a question not a declaration. Faced with a room full of Māori and Pākehā artists and academics whose own presentations had been devoted to virtues of papering over the postcolonial cracks in performance theory and practice, we (intentionally) caused a small uproar. We pressed on. Our next joint presentation - 'Māori Performance/Cultural Performance:

Sharon Mazer is Associate Professor in Theatre \& Performance Studies at Auckland University of Technology. 
Stages of Pōwhiri' - was some six or seven years in the making and sparked an outcry over Te Rita's critique of the encroachment of theatricality into the pre-festival pōwhiri. In 2013, controversy erupted at the Kowwhiti Atarau Contemporary Indigenous Dance Symposium both when Te Rita made the case for Kapa Haka as a contemporary dance form and when we refused to countenance the decolonisation of Te Matatini stage. We continue to present and publish together as well as separately, taking pleasure in what we can find out by provoking ourselves, each other and our readers/listeners.

Our presentations and publications have been distinctive for the way we apply diverse theories to our analyses of Kapa Haka and other forms of Māori performance from our particular perspectives: Te Rita as a prominent performer, teacher, judge and commentator on Kapa Haka, and I as a trained theatre director and performance ethnographer. More than anything, Te Rita's doctoral thesis, completed just over three years ago, has set the stage for other academics to expand the field exponentially. ${ }^{1}$ We look at Māori performance from ritual to Kapa Haka, from the marae to the stage to just about everywhere else, for the way ideas about Māori culture and identity are constructed and communicated. We look at what is given to be looked at, and we look at who we are to be looking, how we are looking and what it means to be looking.

We weren't the only ones, of course, or even the first, really. Charles Royal's PhD thesis on whare tapere appeared in 1998, and Christopher Balme's book, Decolonizing the Stage, hit the shelves in 1999. At about the same time, Indigenous Performance Research in various forms began to take off, particularly in the USA and Canada. I can recall, for example, reviewing an anthology of Contemporary Plays by Women of Color, edited by Kathy Perkins and Roberta Uno, that appeared in 1996. It included a number of plays by Native American playwrights alongside plays by African American and Latina writers, and the editors were both sharp and careful in recognising the issues particular to such alignments. But Charles Royal was dismissive of Kapa Haka, and Christopher Balme was superficial. And so we were the first to look - really look - at Kapa Haka as performance, to link the performance of Kapa Haka to its roots both in ritual and in performance for

\footnotetext{
${ }^{1}$ For examples of Māori Performance Research related thesis work to emerge from Theatre and Film Studies at the University of Canterbury, see also Johnston (2007) and Hamilton (2010).
} 
tourists, and to take what happens in rehearsal and performance seriously as indicative of deeper, more urgent social meanings, attachments and actions.

That was then.

Now, it is possible to see a field of study. Call it (at least for now) Māori Performance Research. Informed by the principles both of Kaupapa Māori research and of Performance Studies, this field has been expanding exponentially over the past decade or so - well beyond my own ability to keep up, especially as an obvious outsider to the language and culture. There's an extensive bibliography - four and a half pages! attached to a lengthy report on 'The Benefits of Kapa Haka' commissioned by Te Matatini and published in 2014. Most of the readings cited were published after the year 2000: over fifty items by my (probably faulty) count. The report doesn't include the papers published in 2015 following Köwhiti Atarau (Wellington 2013). Nor does it capture the dozen articles published in Te Kaharoa following Empowering Performance, the first Ka Haka! Māori and Indigenous Performance Studies Symposium (AUT 2016). And that's just what I've been in the room for.

What are the inclinations of this emergent field and its implications for the way we think not only about the history and present practice of Māori performance, but also Indigenous performance more widely? How might Māori Performance Research, in fact, come to contribute to Performance Studies itself, perhaps even transform some longstanding assumptions about the relationship between international and local scholarship in ways that are meaningful and useful? These questions are only now coming into focus and starting to play out as the conversation expands.

Some of the most remarkable performance research by new and emerging Māori scholars is already going international. I'd like to highlight one colleague in particular: Nicola Hyland (Te Atihaunui-a-Pāpārangi, Ngati Hauiti) at Victoria University. Hyland writes about both theatre and performance, with a keen eye for detail and skilful analysis that never fails to provoke me past what I already (think I) know into new understandings. We first crossed paths at the 2014 Australasian Association for Theatre, Drama and Performance Studies conference (Victoria University). It was an accident. I was chairing a panel in which she presented an early version of her paper, 'Beyoncé does the haka'. I thought I 
knew where she would take us: a sharp rebuke of cultural appropriation supported by a display of cultural knowledge by someone of the culture rightly defending the culture against incursion. I've seen enough of that, and as someone who has capitalised on incursing in such ways I was prepared to be both on side and put in my place. But no. What Hyland did in her paper and then went on to develop fully for an article in TDR/The Drama Review - the top Performance Studies Journal - was more complicated and challenging than that. She showed us Beyoncé's emulation of the haka, the controversy that erupted in response, and her own evaluation: 'Beyoncé's response [she argues] is a reaction unbound by cultural protocols: an organic reply to a spontaneous act. It reinforces the vital power of the performer-spectator relationship in making haka meaningful [. . .]'. She goes on: '[I]t also reconfigures what indigenous performance can be when it is not bound by the constraints of the authentic or traditional: when a response is measured by a mutual energetic flow, rather than a perceived cultural imperative' (67). Fluent both in te reo Māori and in Māori performance, Hyland uses her analysis of this odd cultural encounter to trouble the notion of cultural rules, of 'tradition'. She's not uncritical. In fact, she pits Beyoncé's engagement with haka against that of Rhianna, who she says 'sought an indigenous performance to satisfy a demonstrated fetish for otherness' (81). What Hyland achieves is a provocation that pushes us past the present example to question what we bring to the act of looking, the assumptions that lead us to read what we see into pre-set ideological frames.

At risk of sounding like a fan girl, indulge me in presenting another example of how Hyland is creating a new way of doing Māori Performance Research: her acute, persuasive reading of Hone Kouka's recent experimental play, The Beautiful Ones - a production I saw (and didn't much like) when it premiered in Wellington (Circa Theatre 2015). I'm having to re-think my response to the performance in light of Hyland's article for New Theatre Quarterly. In 'Young, Gifted, and Brown: The Liberation of Oceanic Youth in The Beautiful Ones' (2016), Hyland sees Kouka's depiction of Māori and Pacific young people at an all-night dance party as 'luminous' and 'liberated'. What I saw as a bit of a hot mess, Hyland identifies as 'a digital, indigenous performance text that weaves together multiple forms and styles to create a bold new dramaturgy' (333). For Hyland, 'The production not only 
[defied] genre, but [challenged] enduring, moralistic lore about the ways "young, brown folk" should be represented in the theatre' (333). She meticulously walks the reader through the elements of the production, from its setting, music and choreography to its text and performers. She sets it into multiple contexts: Kouka's earlier work and that of other trailblazing Māori playwrights; haka (Māori performing arts); social and theoretical. In so doing, Hyland has forced me to go back to the production, to re-imagine it from her, and their, vantage point. 'The work', she says, 'revels in the passionate indeterminacy of youth' (337) in form as well as content. In creating a 'pan-tribal form of movement [it breaks] down the homogenizing binaries of Western cultural discourse' (344). What she sees, what she tells me, is that the production wasn't for me. If I didn't get it, well then . . .

Dr Hyland is currently working on a research project titled 'The Māori Method: The Whakapapa of Māori Performance'. I intend to be in the front row when she presents the results, and I am prepared to take a back seat as she leads the next wave of Māori Performance Research. She is an academic force to be reckoned with. And she is not the only one. My colleagues in Te Ara Poutama, the Faculty of Māori and Indigenous Development at AUT, are producing remarkably diverse scholarship. You've heard Maree Sheehan present the keynote that preceded this panel. Sitting here with us today is Dr Jani Wilson, whose work on the representation of Māori in New Zealand film is breaking new ground, as is her development of a Mahi Toi approach to research. You'll be hearing from many others in the next few days. The future is theirs. 


\section{References}

Balme, Christopher. Decolonizing the Stage: Theatrical Syncretism and Post-colonial Drama Clarendon Press: 1999.

Cleave, Peter (ed). Kōwhiti Atarau. Palmerston North: Go Press, 2015.

Hamilton, Mark James. 'Martial Dance Theatre: A Comparative Study of Torotoro Urban Māori Dance Crew (New Zealand) \& Samudra Performing Arts (India)'. PhD thesis, University of Canterbury, 2010.

Hyland, Nicola. 'Beyoncé's Response (eh?): Feeling the Ihi of Spontaneous Haka Performance in Aotearoa/New Zealand'. TDR/The Drama Review 59.1 (2015): 67-82.

-----. 'Young, Gifted, and Brown: The Liberation of Oceanic Youth in The Beautiful Ones' New Theatre Quarterly 32.4 (2016): 333-346.

Johnston, Emma. 'Healing Māori Through Song and Dance? Three case studies of recent New Zealand music theatre'. MA thesis, University of Canterbury, 2007.

Mazer, Sharon, and Te Rita Papesch, 'Māori Performance/Cultural Performance: Stages of Pōwhiri'. Presented at Ngā Kete a Rēhua: Inaugural Māori Research Symposium - Te Waipounamu, September 2008. Published in proceedings, 2010.

-----. 'But can it be Art? Kapa Haka as a contemporary indigenous performance practice'. Te Kaharoa 8 (2015): 105118.

Mazer, Sharon. 'A Case for Creative Misunderstanding'. Te Kaharoa 8 (2015): 87-104.

Mazer, Sharon (ed.). 'Ka Haka: Empowering Performance.' Proceedings of the $2016 \mathrm{Ka}$ Haka Māori \& Indigenous Performance Studies Symposium, AUT. https://www.tekaharoa.com/index.php/tekaharoa/article/vie $\underline{\mathrm{w} / 3 / 2}$. 
Ngā Hua a Tāne Rore / The Benefits of Kapa Haka: Scoping the research needs and options for developing a better understanding of the contribution that Kapa Haka makes to Aotearoa New Zealand society. Scoping Report for Te Manatū Taonga and Te Matatini. June 2014.

Papesch, Te Rita. 'Creating a Modern Māori Identity through Kapa Haka'. PhD thesis, University of Canterbury, 2015.

Papesch, Te Rita, and Sharon Mazer, 'Crossing the Cultural Divide'. Footprints/Tapuwae . . Return of the Native, Te Puna Toi: Performance Research Project (Theatre \& Film Studies, University of Canterbury) Christchurch Arts Centre, 2001. http://www.freetheatre.org.nz/te-puna-toi.html.

Perkins, Kathy A., and Roberta Uno (eds). Contemporary Plays by Women of Color. London: Routledge, 1996.

Royal, Te Ahukaramū Charles. 'Te Whare Tapere: Towards a Model for Māori Performing Arts'. PhD thesis, Victoria University of Wellington, 1998.

Wilson, Jani Katarina Taituha. 'Developing Mahi-Toi Theory and Analysis'. MAI Journal 6.2 (2017): 116-128.

Sharon Mazer is Associate Professor of Theatre \& Performance Studies in Te Ara Poutama, the Faculty of Māori and Indigenous Development at Auckland University of Technology. Recent publications include: I have loved me a Man: the life and times of Mika (Auckland University Press 2018); 'New Hazardscapes for Old: Rupture, Resilience, Resistance' (Performance Research 2018); and 'Donald Trump Shoots the Match' (TDR 2018). 